\title{
Hemodynamic during resistance exercise sets and rest intervals in young and older men
}

https://doi.org/10.11606/issn.1981-4690.v35i3p1-7

\begin{abstract}
Intense blood pressure (BP) elevations during resistance exercise (RE) could lead to risk of acute cardiovascular events. Since, the natural aging process contribute to rest and exercise elevations in BP, higher BP elevations following RE could be expected in older individuals. However, previous studies have shown contradictory findings which are likely due to the time of BP assessment following exercise. Thus, we compared BP changes after each set and rest interval in young and older men. Sixteen men (8 each group) underwent four sets until fatigue at leg press equipment with high load (80\% 1RM). BP was assessed, by finger photoplethysmography and the other cardiovascular measurements were estimated based on individual characteristics. Systolic BP (SBP) and mean BP (MBP) increased more in older men at first sets; heart rate (HR) increased more in young during all sets and rest intervals; cardiac output (CO) maintained higher all the time in young; and total peripheral resistance (TPR) increased more during all sets in older men. Thus, the present study shows that RE performed to fatigue leads to higher BP increase in older men suggesting BP might be monitored during RE for safety reasons especially on this higher risk population.
\end{abstract}

KeYwORDs: Aged; Blood pressure; Strength exercise; Cardiovascular response; Aging; Heart rate.

\section{Introduction}

Although, a program of resistance exercise (RE) is recommended for health purposes, vigorous physical activity can cause a transient increase in the risk of acute myocardial infarction and sudden death in susceptible individuals ${ }^{1,2}$; besides offer higher risk than low and moderate intensity exercise even for health individuals. High blood pressure (BP) that can occur during RE could be stimulus for this increased risk ${ }^{3}$. As such, high BP can destabilize atherosclerotic plaques and aneurysms, which may lead to myocardial electrical instability during exercise and/or recovery, and in turn can trigger a myocardial infarction ${ }^{4}$.

It is reasonable to expect that with higher baseline and exercise-related BPs among older individuals that the peak BP observed with RE could also be higher in this population ${ }^{5-7}$.

Previous studies have compared arterial blood pressure responses in young and older individuals during and after RE. VALLEJO et al. ${ }^{8}$ showed higher systolic BP (SBP) peak in older adults compared to young after concentric leg squat, even when it
*Laboratory of Exercise Physiology, Faculty of Physical Education, University of Campinas, Campinas, SP, Brazil.

** Gerontology Program, Faculty of Medical Sciences, University of Campinas, Campinas, SP, Brazil.

${ }^{* * *}$ Sidia Institute of Science and Technology, Manaus, AM, Brazil.

${ }^{* * * *}$ Cerebral and Cardiovascular Physiology Laboratory, Department of Physiology and Anatomy, University of North Texas Health Science Center, Fort Worth, TX, USA.

$* * * * *$ Integrative Physiology Laboratory, University of Illinois at Chicago, Chicago, Illinois, USA 
was adjusted to their individual loads. In contrast, higher SBP and diastolic BP (DBP) have been seen after leg press exercise in young men compared to older men ${ }^{9,10}$. Moreover, other studies, investigating different types of RE did not find differences in the $\mathrm{BP}$ increases between young and older adults ${ }^{7,10}$, leading to inconclusive assumptions.

A variety of factors might elicit such differences. For instance, timing of the BP measurement could parcially explain this discrepancy. Also, BP could increase set after set in different magnitudes, and could also be influenced by the rest interval durations, as well as the ability of $\mathrm{BP}$ to return to baseline during recovery. To demonstrate these points, BP was measured in the last set ${ }^{8}$, while KaWANO et al. ${ }^{9}$ considered the peak BP among all set ${ }^{9}$, and Thiebaud et al. ${ }^{10}$ assessed BP 5 min after the end of exercise ${ }^{10}$, and even the area under the curve during exercise and recovery has been used ${ }^{7}$.

Characterizing BP and related hemodynamic during each set and rest interval responses (i.e. heart rate, stroke volume, cardiac output, and total peripheral resistance) with maximum RE may elucidate the differences between young and older adults. Thus, the present study aimed to compare the effects of high load RE on BP and general hemodynamics between young and older men during each set and rest interval.

\section{Methods}

\section{Participants}

Eight young (18-35 yrs) and 8 older ( $>60 \mathrm{yrs})$ untrained men (no regular RE for a minimum of 6 months) volunteered for this study. Participants were excluded if they had cardiovascular, metabolic, and pulmonary or joint limitations, body mass index $>30 \mathrm{~kg} / \mathrm{m}^{2}$, if they were smokers, or if they were under the use of any medication that could influence the cardiovascular responses investigated herein. A cardiologist carried out a clinical examination including an electrocardiogram during rest and during the RE testing. All the participants provided written informed consent approved by the research ethics committee from the university and the study was carried out according to Declaration of Helsinki.

\section{Experimental design}

Participants underwent four visits. In the first, weight, height, questionnaires and the clinical exams were done. In the second, participants underwent a familiarization RE session and the one-repetition maximum (1RM) test. On the third, they underwent $1 \mathrm{RM}$ retest (after at least $72 \mathrm{~h}$ ). Lastly, on the fourth visit, participants performed the RE protocols in the morning (between $7 \mathrm{am}$ and $12 \mathrm{pm}$ ), in a temperaturecontrolled $\left(23^{\circ} \mathrm{C}\right)$ environment according to SARDELI et al. ${ }^{11}$. In this fourth visit, following a warm-up of 10 repetitions at 30\% 1RM, 4 sets of RE at $80 \% 1 \mathrm{RM}$ were performed on a leg press machine (Nakagym, São Paulo, Brazil) at $45^{\circ}$, until fatigue, with 1 -min rest interval between sets (feet resting on the ground).

\section{Maximum strength test}

One-repetition maximum (1RM) was used to assess maximal strength on a leg press machine (Nakagym, Brazil), as previously described ${ }^{12}$. Participants performed a general 5-min low-load warm-up on a cycle ergometer, followed by specific warm-up composed of 8 repetitions at $50 \%$ of their estimated 1RM and 3 repetitions at $70 \%$ of their estimated 1RM, separated by 3 min rest period. Following the warm up participants performed 5 trials of 1RM, with 3 to 5 min of rest between trials. The value of the highest load obtained after the test and retest was recorded for exercise prescription.

\section{Hemodynamic assessments}

Beat-to-beat BP waveforms were continuously recorded pre and during $\mathrm{RE}$ protocol by photoplethysmography (Finometer Pro ${ }^{\oplus}$, Finapres Medical Systems, Arnhem, The Netherlands), with the cuff positioned on the medial phalanx of the middle finger of the right hand ${ }^{13}$. Brachial BP was estimated from the finger blood pressure waveform and analyzed using BeatScope ${ }^{\oplus}$ software (Finapres Medical Systems, Amsterdam, The Netherlands), with a hydrostatic height correction system to compensate for the hand position in relation to the heart. Participants remained at rest seated on the $45^{\circ} \mathrm{leg}$ press machine for pre-exercise assessments, in which an average of 300 heart beats was used. During RE sessions the average of 5 beats at the end of each set and rest interval were analyzed ${ }^{14}$. The end of the set was registered when the participants place their feet on 
the floor. Heart rate (HR), stroke volume (SV), cardiac output $(\mathrm{CO})$ and total peripheral resistance (TPR) were derived from finger $\mathrm{BP}$ waves using the Modelflow method incorporating age, sex, height and body mass (BeatScope ${ }^{\oplus}$, Finapres Medical Systems, Amsterdam, The Netherlands) $)^{15,16}$, and double product (DP) was calculated multiplying SBP by HR.

\section{Statistical analysis}

Shapiro-Wilk test was used to verify normality. The baseline values were compared between groups by independent $t$-tests. To isolate the RE effects, independent of baseline differences, the deltas from pre to each time point were analyzed. A 2-way ANOVA (group (young vs. old) by time (set 1 , rest 1 , set 2 , rest 2 , set 3 , rest 3 and set 4)) was performed for raw data (HR, SV, SBP, DBP, MBP and DP) and transformed data when necessary (CO and TPR)). The GreenhouseGeisser corrections were applied to all variables, since all were significant for sphericity observed in the Mauchly`s test. For post-hoc analyses, Bonferroni was applied (group*time). We considered significant an alpha value $<0.05$. The analyses were performed on PASW Statistics 18.0 software (SPSS Inc., Chicago, USA). Data are described as mean \pm standard deviation.

\section{Results}

Baseline and RE characteristics are described in TABLE 1. Older men were heavier, had higher BMI, and presented higher baseline HR, DBP, mean BP (MBP), DP and TPR with lower SV and CO, compared to the young men. Although, older men reached similar number of repetitions, they performed lower absolute total load (load*repetitions) than the young men (TABLE 1).

TABLE 1 - Baseline and RE characteristics.

\begin{tabular}{llll}
\hline & Young & Older & p value \\
\hline Baseline Characteristics & & & \\
Age (years) & $26 \pm 4$ & $64 \pm 4$ & $<\mathbf{0 . 0 0 1}$ \\
Weight (kg) & $66.5 \pm 7.8$ & $75.1 \pm 8.2$ & $\mathbf{0 . 0 3 5}$ \\
Height (cm) & $172 \pm .05$ & $169 \pm .04$ & 0.304 \\
BMI (kg/cm2) & $22.3 \pm 1.4$ & $26.2 \pm 1.8$ & $<\mathbf{0 . 0 0 1}$ \\
HR (bpm) & $56 \pm 8$ & $64 \pm 7$ & $\mathbf{0 . 0 4 1}$ \\
SV (ml) & $108 \pm 13$ & $86 \pm 15$ & $\mathbf{0 . 0 0 9}$ \\
CO (L/min) & $6.0 \pm .8$ & $5.4 \pm .9$ & 0.219 \\
SBP (mmHg) & $122 \pm 11$ & $132 \pm 13$ & 0.14 \\
DBP (mmHg) & $61 \pm 8$ & $71 \pm 6$ & $\mathbf{0 . 0 2 1}$ \\
MBP (mmHg) & $82 \pm 9$ & $93 \pm 8$ & $\mathbf{0 . 0 2 4}$ \\
DP (mmHg $\times$ bpm) & $6903 \pm 1213$ & $8454 \pm 1163$ & $\mathbf{0 . 0 2 1}$ \\
TPR (dyn.s/cm5) & $1073 \pm 157$ & $1336 \pm 218$ & $\mathbf{0 . 0 1 5}$ \\
RE Characteristics & & & \\
\# of repetitions set 1 & $15 \pm 6$ & $13 \pm 4$ & 0.442 \\
\# of repetitions set 2 & $12 \pm 3$ & $10 \pm 2$ & 0.061 \\
\# of repetitions set 3 & $9 \pm 2$ & $10 \pm 2$ & 0.234 \\
\# of repetitions set 4 & $7 \pm 2$ & $9 \pm 3$ & 0.64 \\
\# of total repetitions & $43 \pm 9$ & $41 \pm 7$ & 0.617 \\
Load (Kg) & $262.2 \pm 66.8$ & $181.1 \pm 33.7$ & $\mathbf{0 . 0 1 3}$ \\
Total Load & $10,921 \pm 4,201$ & $7,488 \pm 2,040$ & $\mathbf{0 . 0 4 5}$ \\
\hline
\end{tabular}

Legend:

RE: Resistance exercise BMl: Body mass index; HR: heart rate;

SV: stroke volume; CO: cardiac output; SBP: systolic blood pressure; DBP: diastolic blood pressure;

MBP: mean blood pressure;

DP: double product; TPR: total peripheral resistance; Total load: load * repetitions; \#: number. 


\section{Legend:}

HR: heart rate;

SV: stroke volume;

CO: cardiac output;

TPR: total peripheral resistance;

SBP: systolic blood pressure;

DBP: diastolic blood pressure;

MBP: mean blood pressure.

*: difference between older and young $(\mathrm{p}<0.05)$.
FIGURE 1 shows greater increase in HR for young men compared to older men at all time points; higher SBP increase for older men during sets one and two; and higher TPR increments in older men across all sets. Furthermore, there were group effects for lower SV $(\mathrm{p}=0.051)$ and $\mathrm{CO}(\mathrm{p}<0.001)$ in older men.

FIGURE 1 - Delta of cardiovascular responses for each set and rest interval during HL for older and young.
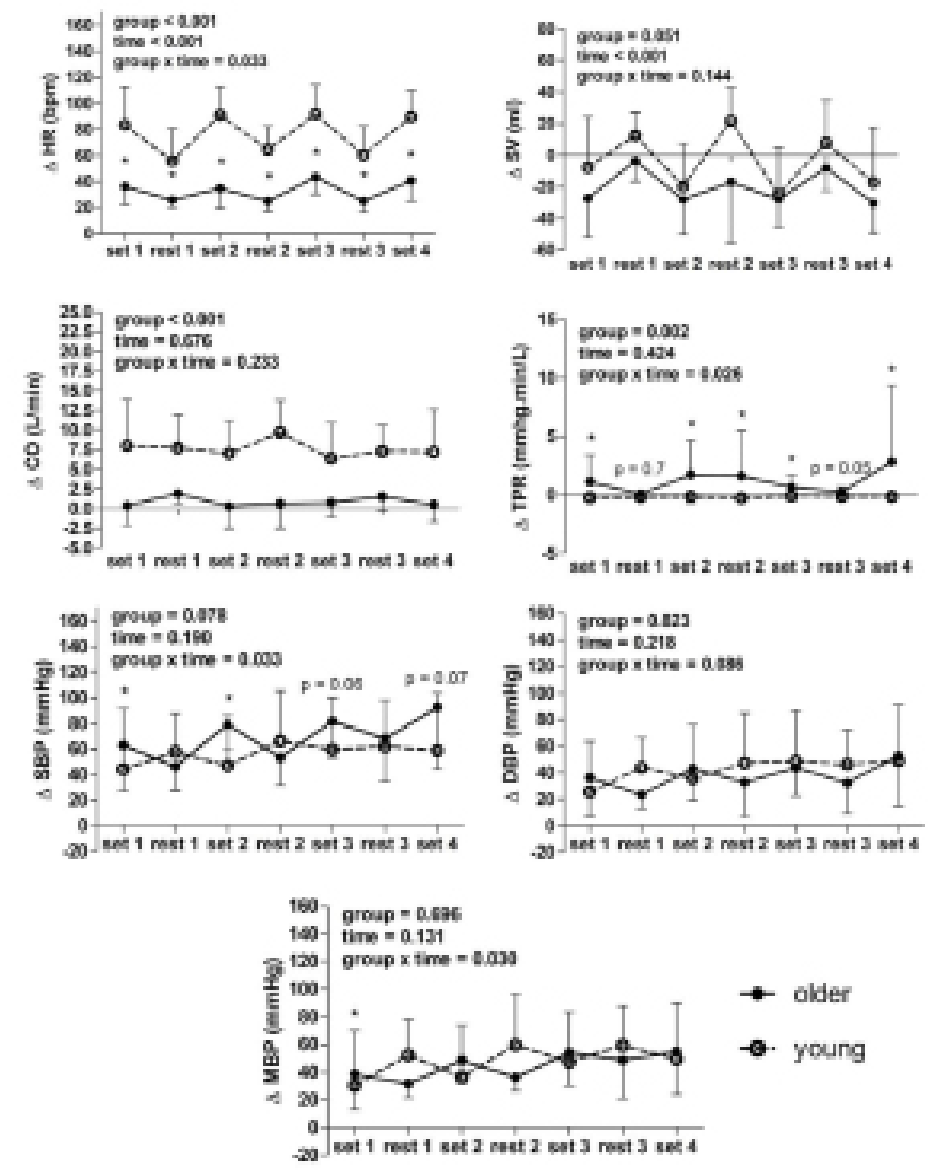

\section{Discussion}

We believe this is the first study to compare $\mathrm{BP}$ responses during $\mathrm{RE}$ sets and rest between young and older men. In summary, older men showed higher SBP and TPR increments during RE sets, while young men showed higher HR, SV and subsequently CO during both sets and rest intervals.

Because BP changes according to $\mathrm{CO}$ and TPR, the higher SBP and MBP in older adults were likely caused by increased TPR only during sets, while $\mathrm{CO}$ was very stable during exercise session. CO increment during exercise is a result of SV and HR rises ${ }^{17}$. The increase in SV appears to be limited during sets, and as such the increase in HR explains the rise in CO for both groups. However, during rest intervals, $\mathrm{CO}$ is rather stable throughout the session, due to increases in SV and coupled reductions in HR.

Chronotropic incompetence, which can occur with aging, may partially explain the attenuated delta HRs during both sets and rest in the older men. As such, chronotropic incompetence has been associated to both intrinsic heart rate changes and reduced $B$-adrenergic sensitivity ${ }^{18}$. Reduced autonomic nervous system (ANS) responsiveness has also been observed in individuals with lower exercise capacity and sympathetic activity is less determinant during 
maximum performance in untrained individuals; which could explain the present results once older men were likely more sedentary and untrained than our young men ${ }^{19,20}$. However, since ANS modulation was not measured in the present study, it is not possible to state which physiological mechanisms explain such findings.

Additionally, greater SV reductions in older men $(\mathrm{p}=0.051)$ seems to be partially mediated by TPR increase, especially during sets, once it would lower venous return to the heart and impair pre-load, necessary for Frank-Starling efficiency. Indeed, it is well established that older adults have stiffer vessels and poor endothelial function compared to their younger counterparts that could cause higher TPR, although arterial stiffness or endothelial function were not assessed herein ${ }^{21}$.

During exercise, high elevations on BP are expected due to parasympathetic withdrawal, higher sympathetic outflow through neural feedback sent from skeletal muscle receptors and neuronal input from central command ${ }^{22}$. During rest, neural control, venous return from muscle relaxation and reduction in intrathoracic pressure would contribute to SBP and DBP reduction. In the present study, the increase in SBP and MBP were higher in older men during the first sets, but along the RE session this difference was reduced. A possible explanation for this finding could be the reduced baroreflex sensitivity in older adults ${ }^{23}$. The carotid and aortic baroceptors, important to the fast BP regulation, should prevent higher BP elevations during rest and in the onset of exercise, but the progressive muscle metaboreflex activation gradually decreases its sensitivity enabling higher BP increases along exercise session ${ }^{24}$. This baroreceptor regulation that is more evident in the beginning of exercise, might explain the discernibility between older and young BP changes in the first sets.

This study presented some limitations. The first one was the small number of participants. However, the effects appeared even in this small sample. Another limitation was the inclusion of recreationally active men in the younger group, and as such, observed differences could be due to a possible interaction between age and fitness levels.

Older men had larger SBP and MBP increase during the first sets, likely due to higher TPR increase, once $\mathrm{CO}$ was maintained in older and was higher in young men. This lack of physiological control for BP increase in the onset of RE could be associated with an impairment in baroreceptor sensitivity in older population, since it regulates the fast BP response and the increment in the last sets were similar to young men. Thus, the present study shows that RE performed to fatigue leads to higher $\mathrm{BP}$ increase in older men suggesting BP might be monitored during RE in this higher risk population.

\section{Acknowledgments}

Amanda Veiga Sardeli and Marina Lívia Venturini Ferreira were supported by Coordenação de Aperfeiçoamento de Pessoal de Nível Superior (Capes) Foundation. Lucas do Carmo Santos, Arthur Fernandes Gáspari, Cláudia Regina Cavaglieri and Mara Patrícia Traina Chacon-Mikahil were recipient of Conselho Nacional de Desenvolvimento Científico e Tecnológico (CNPq) Fellowship.

\section{Disclosure of interest}

The authors report no conflict of interest.

\section{Disclosure statement}

This is to acknowledge any financial interest or benefit that has arisen from the direct applications of your research. 


\section{Resumo}

Elevações intensas da pressão arterial (PA) durante o exercício resistido (ER) podem levar ao risco de eventos cardiovasculares agudos. Uma vez que o processo natural de envelhecimento contribui para elevações da PA em repouso e exercício, podem ser esperadas maiores elevações PA após ER em indivíduos mais velhos. No entanto, estudos anteriores mostraram achados contraditórios que provavelmente se devem ao tempo de avaliação da PA após o exercício. Assim, comparamos as alterações da PA após cada série e intervalo de descanso em homens jovens e mais velhos. Dezesseis homens (8 em cada grupo) foram submetidos a quatro séries até a fadiga no equipamento leg press com alta carga (80\% 1RM). A PA foi avaliada por fotopletismografia digital e as demais medidas cardiovasculares foram estimadas com base nas características individuais. A PA sistólica (PAS) e a PA média (PAM) aumentaram mais em homens mais velhos nas primeiras séries; a frequência cardíaca (FC) aumentou mais nos jovens durante todas as séries e intervalos de descanso; o débito cardíaco (DC) manteve-se sempre mais alto nos jovens; e a resistência periférica total (RPT) aumentou mais durante todas as séries em homens mais velhos. Assim, o presente estudo mostra que o ER realizado até a fadiga leva a um maior aumento da PA em homens mais velhos, sugerindo que a PA pode ser monitorada durante o ER por razões de segurança, especialmente nesta população de maior risco.

Palavras-chave: Idoso; Pressão arterial; Exercício de força; Resposta cardiovascular; Envelhecimento; Frequência cardíaca.

\section{References}

1. Thompson PD, Franklin BA, Balady GJ, et al. Exercise and acute cardiovascular events placing the risks into perspective: a scientific statement from the American Heart Association Council on Nutrition, Physical Activity, and Metabolism and the Council on Clinical Cardiology. Circulation. 2007;115:2358-68.

2. Williams MA, Haskell WL, Ades PA, et al. Resistance exercise in individuals with and without cardiovascular disease: 2007 update: a scientific statement from the American Heart Association Council on Clinical Cardiology and Council on Nutrition, Physical Activity, and Metabolism. Circulation. 2007;116:572-84.

3. MacDougall JD, Tuxen D, Sale DG, et al. Arterial blood pressure response to heavy resistance exercise. J Appl Physiol. 1985;58:785-790.

4. Albert CM, Mittleman MA, Chae CU, et al. Triggering of sudden death from cardiac causes by vigorous exertion. N Engl J Med. 2000;343:1355-1361.

5. Miall WE, Lovell HG. Relation between change of blood pressure and age. Br Med J. 1967;2:660-4.

6. Sabbahi A, Arena R, Kaminsky LA, et al. Peak Blood Pressure Responses During Maximum Cardiopulmonary Exercise Testing. Hypertension. 2018;71:229-236.

7. Vieira PJC, Chiappa GR, Umpierre D, et al. Hemodynamic responses to resistance exercise with restricted blood flow in young and older men. J Strength Cond Res. 2013; 7:2288-94.

8. Vallejo AF, Schroeder ET, Zheng L, et al. Cardiopulmonary responses to eccentric and concentric resistance exercise in older adults. Age Ageing. 2006;35:291-297.

9. Kawano H, Nakagawa H, Onodera S, et al. Attenuated increases in blood pressure by dynamic resistance exercise in middle-aged men. Hypertens Res. 2008;31:1045-1053.

10. Thiebaud RS, Fahs CA, Rossow LM, et al. Effects of age on arterial stiffness and central blood pressure after an acute bout of resistance exercise. Eur J Appl Physiol. 2016;116:39-48.

11. Sardeli AV, do Carmo Santos L, Ferreira M, et al. Cardiovascular responses to different resistance exercise protocols in elderly. Int J Sports Med. 2017;38:928-936.

12. Brown LE, Weir J. ASEP Procedures recommendation I: Accurate assessment of muscular strength and power. J Exerc Physiol Online. 2001;4:1-21.

13. Guelen I, Westerhof BE, van der Sar GL, et al. Validation of brachial artery pressure reconstruction from finger arterial pressure. J Hypertens. 2008;26:1321-1327. 
14. van der Velde N, van den Meiracker AH, Stricker BHC, et al. Measuring orthostatic hypotension with the Finometer device: is a blood pressure drop of one heartbeat clinically relevant? Blood Press Monit 2007;12:167-71.

15. Sugawara J, Tanabe T, Miyachi M, et al. Non-invasive assessment of cardiac output during exercise in healthy young humans: comparison between Modelflow method and Doppler echocardiography method. Acta Physiol Scand. 2003; 179:361-6.

16. Stok WJ, Baisch F, Hillebrecht A, et al. Noninvasive cardiac output measurement by arterial pulse analysis compared with inert gas rebreathing. J Appl Physiol. 1993;74:2687-2693.

17. Zhou B, Conlee RK, Jensen R, et al. Stroke volume does not plateau during graded exercise in elite male distance runners. Med Sci Sports Exerc. 2001;33:1849-54.

18. Christou DD, Seals DR. Decreased maximal heart rate with aging is related to reduced $\beta$-adrenergic responsiveness but is largely explained by a reduction in intrinsic heart rate. J Appl Physiol. 2008;105:24-29.

19. Svedenhag J, Henriksson J, Juhlin-Dannfelt A, et al. Beta-adrenergic blockade and training in healthy men-effects on central circulation. Acta Physiol Scand. 1984;120:77-86.

20. Joyner MJ, Freund BJ, Jilka SM, et al. Effects of beta-blockade on exercise capacity of trained and untrained men: a hemodynamic comparison. J Appl Physiol. 1986;60:1429-1434.

21. Scuteri A, Tesauro M, Di Daniele N. Preventive geriatrics the cross-talk between arterial and brain aging: a lifelong condition. Exp Gerontol. 2017;87:148-150.

22. Fisher JP, Young CN, Fadel PJ. Autonomic Adjustments to Exercise in Humans. Hoboken, NJ, USA: John Wiley \& Sons, Inc.

23. Milan-Mattos JC, Porta A, Perseguini NM, et al. Influence of age and gender on the phase and strength of the relation between heart period and systolic blood pressure spontaneous fluctuations. J Appl Physiol. 2018;124:791-804.

24. Sala-Mercado JA, Ichinose M, Coutsos M, et al. Progressive muscle metaboreflex activation gradually decreases spontaneous heart rate baroreflex sensitivity during dynamic exercise. Am J Physiol Circ Physiol. 2010;298:H594-H600.

\begin{tabular}{r|c} 
ADDREss & \\
Amanda Veiga Sardeli & \\
Laboratory of Exercise Physiology & \\
Faculty of Physical Education & Submitted: 06/24/2020 \\
University of Campinas & Accepted: 12/20/2021 \\
Av. Érico Veríssimo 701 & \\
$13083-851$ - Campinas -SP - Brazil & \\
&
\end{tabular}

